\title{
Upper cervical spine fusion in the pediatric population
}

\section{David W. Lowry, M.D., Ian F. Pollack, M.D., Brent Clyde, M.D., A. Leland Albright, M.D., and P. David Adelson, M.D.}

Department of Neurological Surgery, University of Pittsburgh, Children's Hospital of Pittsburgh, Pittsburgh, Pennsylvania

The outcomes of 25 pediatric patients who underwent upper cervical or occipitocervical fusion at the authors' institution since 1983 were reviewed. At a mean age of 9 years, the patients presented with spinal instability that was associated with os odontoideum in 11 cases, rotatory subluxation in five cases, odontoid fracture in two cases, atlantooccipital dislocation in two cases, and congenital atlantoaxial instability in five patients, four of whom had Down's syndrome (trisomy 21). Ten children had abnormal findings on neurological examination preoperatively; however, nine experienced improvement or resolution of deficits as of their latest follow-up evaluation (mean 17 months). Fusion was achieved with the first operation in 21 of 25 patients; eventually it was attained in all but one. Four patients exhibited persistent spinal instability after an initial procedure. This was caused by erosion of a multistranded cable through the intact arch of $\mathrm{C}-2$ in two cases, by pin site infection necessitating early halo removal in one case, and by slippage in a halo following a Gallie procedure, which was revised with a Brooks fusion in one case. This series, the largest yet published, shows that with appropriate surgical management, posterior upper cervical fusion in the pediatric population is highly successful. Careful attention to halo pin site care and caution in using multistranded cable in young patients may improve results.

\section{Key Words * cervical fusion * atlantoaxial stabilization * atlantoaxial fusion * Down's syndrome * halo vest $*$ children}

Upper cervical instability may occur in children for several reasons. First, traumatic injuries to the pediatric cervical spine tend to involve the first two vertebrae, rather than the inferior cervical spine as is the case in adults. $[1,10,13,18,21]$ Second, instability at this level may be congenital; it tends to be diagnosed early in life, especially in patients with Down's syndrome in whom screening cervical radiographs are now often required before participation in certain physical activities. Third, several rheumatological and connective tissue disorders, including juvenile rheumatoid arthritis, juvenile ankylosing spondylitis, seronegative enthesopathy and arthropathy syndrome, and Morquio's syndrome, can present accompanied by instability at this level.[5,6,11,12,14,30] Finally, os odontoideum with associated atlantoaxial instability often manifests during childhood with the onset of a neurological deficit or neck pain after minor trauma. $[4,8,9,15,26]$ Because of the paucity of data regarding the success of upper cervical fusion in the pediatric population, we reviewed our series of 25 children treated surgically for upper cervical instability.

\section{CLINICAL MATERIAL AND METHODS}




\section{Patient Population}

The surgical case records of the Department of Neurosurgery from 1983 onward were reviewed to find all cases in which a cervical fusion procedure had been performed in a person under 18 years of age. Twenty-five patients were found to have undergone posterior upper cervical fusion (Table 1). The mean patient age at the time of presentation was 9.4 years (range 3-16 years), and both genders were represented (11 boys and 14 girls).

\begin{tabular}{|c|c|c|c|c|c|c|}
\hline & PrEOPER & TWE INDICATIONS ANI & $\begin{array}{l}\text { TABLE } 1 \\
\text { VPE OF SURGERV IN } 25 \text { PL } \\
\text { PER CERVICAL FUSION* }\end{array}$ & ED HTT & RIC PATIEN & REQUR NG \\
\hline $\begin{array}{l}\text { Case } \\
\text { No. }\end{array}$ & $\begin{array}{c}\text { Age [ns], } \\
\text { Sex }\end{array}$ & $\begin{array}{l}\text { Diagnoses at } \\
\text { Presentation }\end{array}$ & $\begin{array}{c}\text { Irilial } \\
\text { Neurdogical Exam }\end{array}$ & $\begin{array}{l}\text { Sur- } \\
\text { geon }\end{array}$ & $\begin{array}{l}\text { Levels in } \\
\text { Construct }\end{array}$ & Construct Type \\
\hline 1 & $5, F$ & $\mathrm{AOD}$ & $\begin{array}{l}\text { rt hemi paresis (0-15), } \\
\text { rt Horner's, it hemidi- } \\
\text { aphragm paralysis }\end{array}$ & 1 & $\mathrm{Oc}-\mathrm{C} 2$ & sutlam $c-1 \& c 2$ \\
\hline 2 & $13, M$ & $\begin{array}{l}\text { type II odontoid } \\
\text { fracture }\end{array}$ & intact & 1 & C1-2 & Erooks \\
\hline 3 & $6, F$ & $\begin{array}{l}\text { c1-2 rotatory } \\
\text { sutluxation }\end{array}$ & intact & 5 & C1-2 & triple wire \\
\hline $\begin{array}{l}4 \\
5\end{array}$ & $\begin{aligned} 3, \mathrm{~F} \\
12, \mathrm{~F}\end{aligned}$ & $\begin{array}{l}\text { os odontoideum } \\
\text { os odontoideum }\end{array}$ & $\begin{array}{l}\text { intact } \\
\text { intact }\end{array}$ & $\begin{array}{l}1 \\
2\end{array}$ & $\begin{array}{l}\text { C1-2 } \\
\text { c1-2 }\end{array}$ & $\begin{array}{l}\text { Erooks } \\
\text { Brooks }\end{array}$ \\
\hline 6 & $3, M$ & $\begin{array}{l}\text { trisom y } 21, c 1-2 \\
\text { instatility }\end{array}$ & intact & 2 & c1-2 & Brooks \\
\hline 7 & $10, M$ & os odontoideum & $\begin{array}{l}\text { decreased proprioce p- } \\
\text { tion, hyperreflexia } \\
\text { tilat LF }\end{array}$ & 6 & C1-2 & Erooks \\
\hline 8 & $6, M$ & os odontoideum & in tact & 1 & C1-2 & Erooks \\
\hline 9 & 9, M & $\begin{array}{l}\text { os odontoideum, } \\
\text { VA dissection }\end{array}$ & $\begin{array}{l}\text { rt CN VII palsy, rt nys- } \\
\text { tagmus, rt dysmetria }\end{array}$ & 1 & c1-2 & Erooks \\
\hline 10 & $5, F$ & $\begin{array}{l}\text { trisom y } 21, \alpha c- \\
\text { C1 \& C1-2 } \\
\text { instability }\end{array}$ & bilat LE hyperreflexia & 1 & $\infty-\infty 2$ & $\begin{array}{l}\text { \#22 ga wire sub- } \\
\text { lam } \mathrm{C1-2} \# 18 \\
\text { ga } \mathrm{Cl}-\mathrm{C2}\end{array}$ \\
\hline 11 & $4, F$ & os odontoideum & intact & $\frac{2}{2}$ & $\begin{array}{l}\mathrm{C1}-2 \\
\infty-\infty\end{array}$ & Erooks \\
\hline 12 & $16, M$ & os odontoideum & It hemi paresis & $\frac{2}{2}$ & $\begin{array}{l}\mathrm{C} 1-2 \\
\mathrm{c} 1-2\end{array}$ & $\begin{array}{l}\text { Gallie } \\
\text { Erooks }\end{array}$ \\
\hline 13 & $15, F$ & $\begin{array}{l}\text { trisom y } 21, c 1-2 \\
\text { instatility }\end{array}$ & tilat LE hyperreflexia & 1 & $c 1-2$ & Brooks \\
\hline 14 & $13, F$ & os odontoideum & intact & 1 & c1-2 & Brooks \\
\hline 15 & $10, F$ & $\begin{array}{l}\text { C1-2 rotatory sub- } \\
\text { luxation }\end{array}$ & intact & 1 & c1-2 & Erooks \\
\hline 16 & $8, M$ & $\begin{array}{l}\text { congenital } \mathrm{Cl}-2 \\
\text { instability }\end{array}$ & dysphagia, hemiparesis & 1 & ToO & \\
\hline 17 & $6, M$ & $\begin{array}{l}\text { JRA, c1-2 rotatory } \\
\text { subluxation }\end{array}$ & intact & $\begin{array}{l}1 \\
2\end{array}$ & $\begin{array}{l}\text { C1-2 } \\
\text { c1-2 }\end{array}$ & $\begin{array}{l}\text { Erooks } \\
\text { Gallie }\end{array}$ \\
\hline 18 & $9, F$ & $\begin{array}{l}\text { c1-2 rotatory } \\
\text { subluxation }\end{array}$ & intact & 2 & c1-2 & Erooks \\
\hline 19 & $12, M$ & os odontoideum & in tact & 3 & c1-2 & Brooks \\
\hline 20 & $9, F$ & $\begin{array}{l}\text { type II odontoid } \\
\text { fracture }\end{array}$ & intact & 3 & & $\begin{array}{l}\text { Erooks w/multi- } \\
\text { stranded catle }\end{array}$ \\
\hline 21 & $11, F$ & AOD & $\begin{array}{l}\text { CN IX, } X, X I, X I I \text { deficits, } \\
\text { rt hemiplegia. }\end{array}$ & 2 & $\begin{array}{c}\alpha-c 3 \\
\alpha-c 2\end{array}$ & $\begin{array}{l}\text { pediatric CD rods } \\
\text { multistranded ca- } \\
\text { tle; sutlam } \mathrm{C-2}\end{array}$ \\
\hline 22 & $14, F$ & $\begin{array}{l}\text { trisom y } 21, c 1-2 \\
\text { instability }\end{array}$ & bilat LE hyperreflexia & 4 & $\infty-\infty 2$ & $\begin{array}{l}\text { mult tistranded ca } \\
\text { tle; sublam } c-2\end{array}$ \\
\hline 23 & $14, M$ & os odontoideum & in tact & 4 & $\mathrm{C1}-2$ & $\begin{array}{l}\text { Erooks w/multi- } \\
\text { stranded catle }\end{array}$ \\
\hline ג & th $\mathrm{c}$ & ...... & & a & & \\
\hline
\end{tabular}




\begin{tabular}{|c|c|c|c|c|c|c|}
\hline$\angle 4$ & $\mathrm{IU}, \Gamma$ & $\begin{array}{l}\text { I-c rula wory sub } \\
\text { lusation }\end{array}$ & IrI lanti & 0 & $\cup 1-c$ & $\begin{array}{l}\text { cruoks wh mul u- } \\
\text { stranded cable }\end{array}$ \\
\hline 25 & 13, M & os odontoideum & rt hemiparesis & 3 & $\mathrm{C} 1-2$ & $\begin{array}{l}\text { Brooks w/mult- } \\
\text { stranded cable }\end{array}$ \\
\hline
\end{tabular}

\section{Patient Presentations}

Of the 15 patients presenting with normal findings on examination, all but one had neck pain. Three patients presented with hyperreflexia alone. One patient presented with normal motor examination responses, but decreased proprioception in his lower extremities. Although 15 children presented without neurological deficit, only one was totally asymptomatic. A total of eight children in the study had neck pain and one reported interscapular pain. A 3-year-old boy with Down's syndrome had been noted to have a right head tilt for 1 year, but he did not have rotatory subluxation. One patient with os odontoideum had experienced whole body dysesthesias transiently after a dive into a shallow pool and another had a transient monoparesis. These deficits had fully resolved by presentation in both cases. One patient with a Type II odontoid fracture had experienced transient mild quadriparesis that fully resolved by presentation.

Ten children had abnormal neurological findings at presentation (Table 1). Three were hyperreflexic without associated motor or sensory deficits. Three had lower cranial nerve deficits, accompanied by hemiparesis in two patients. Three other children also presented with a form of myelopathy, and another presented with sensory deficits only but normal motor responses. Three children presented with deficits referable to regions of the neuroaxis above the foramen magnum. An 8-year-old boy presented with dysphagia and a mild hemiparesis. Another patient presented at the age of 9 years with repeated emesis and ataxia; on examination this child demonstrated unilateral nuclear facial weakness and dysmetria with a contralateral hemiparesis. A third patient, comatose following a severe motor vehicle accident, presented with deficits of the ninth, 10th, 11th, and 12th cranial nerves with hemiparesis. Two other patients presented with hemiparesis.

\section{Radiological Examination}

Plain cervical radiographs (anteroposterior, lateral, and open-mouth odontoid views) were obtained in all patients. Additional lateral views in flexion-extension were obtained in all cases of os odontoideum and congenital instability, but were avoided in the two patients with newly presenting odontoid fractures; the latter injuries were further evaluated using computerized tomography scanning in one case and plain tomography scanning in the other. Plain tomography scanning was also used to evaluate two cases of os odontoideum in lateral views and one case of rotatory subluxation in anteroposterior views.

Computerized tomography and magnetic resonance imaging were used in all but three cases in this series. A single patient was evaluated by means of four-vessel cerebral angiography, which revealed a vertebral artery dissection and subsequent occlusion associated with os odontoideum.

In the cases of os odontoideum determined to be unstable, the atlantodental interval ranged from 6 to 11 $\mathrm{mm}$, whereas movement of the atlas on the axis on flexion-extension views ranged from 4 to $12 \mathrm{~mm}$.

\section{Preoperative Diagnosis}

Atlantoaxial instability associated with os odontoideum was the most common diagnosis following 
clinical and radiographic evaluation and was made in 11 of 25 cases. Atlantoaxial rotatory subluxation was present in five patients, one of whom also had juvenile rheumatoid arthritis. Type II odontoid fractures were newly diagnosed in two patients. Congenital atlantoaxial hypermobility was found in five patients, four of whom had Down's syndrome. Two patients had traumatic atlantooccipital dislocation.

\section{Operative Technique}

After a sedative had been administered, all patients remained conscious while they were intubated using fiberoptic techniques to minimize the risk of inadvertent spinal cord injury. Most children were then placed in a halo orthosis and turned to the prone position. Cervical alignment was confirmed using intraoperative radiography. The operative technique used in 19 children consisted of a Brooks-type fusion, using an interlaminar block of bicortical bone and bilateral sublaminar wires. One case was supplemented with interspinous wires. The Gallie technique was used in two patients: one with rotatory subluxation, but no apparent translational instability, and another with a congenitally narrow canal at C-2. Four patients underwent primary occipitocervical fusion. Autologous iliac crest bone graft was used in each case.

In 19 patients, internal fixation was achieved by using 18-gauge wire. In six children treated more recently, a multistranded cable was used. Somatosensory evoked potential monitoring was used in all patients to detect dorsal column impingement during wire passage. A radiograph was obtained to confirm the alignment at the end of each procedure.

\section{Postoperative Immobilization}

Immobilization was generally continued for 3 months. Postoperatively, one child was immobilized in a hard collar and all others in a halo orthosis. The halo ring was secured using four pins in most cases, with two placed anteriorly in the forehead and two placed posteriorly. When placing the posterior pins, the patient's hair was generally not shaved but rather prepared using iodoform solution. Each pin was tightened using $0.9 \mathrm{~J}(8 \mathrm{in} / \mathrm{lb})$ of torque and retightened 1 day later. Pin care consisted of swabbing each pin site three times daily with half-strength hydrogen peroxide solution.

\section{RESULTS}

\section{Rate of Fusion}

Fusion was achieved in 21 patients (84\%) after the initial operation (Table 2) and in three more patients after a subsequent procedure. Fusion was determined to have taken place on the basis of both a lack of movement on flexion-extension lateral cervical films and the presence of intervening calcified osteoid. The mean radiographic follow-up period was 13 months (range 4-32 months). 


\begin{tabular}{|c|c|c|c|c|c|}
\hline $\begin{array}{l}\text { Case } \\
\text { No. }\end{array}$ & $\begin{array}{l}\text { Levels } \\
\text { Fused }\end{array}$ & $\begin{array}{l}\text { Immo- } \\
\text { bilization } \\
\text { Type }\end{array}$ & $\begin{array}{l}\text { Follow } \\
U_{p} \\
(m \infty)\end{array}$ & Follow-Up Exam & Complications \\
\hline 1 & $\infty c-\infty$ & halo & 76 & $\begin{array}{l}\text { rt UE } 45 ; \text { rt LE } 5 / 5 \text {; It side } \\
55 ; \text { rt LE hyperrefle via. }\end{array}$ & mild scoliosis; rt LE $2.4 \mathrm{~cm}$ short \\
\hline 2 & C1-2 & halo & 5 & in tact & halo pin site infection \\
\hline 3 & $\mathrm{C} 1-2$ & halo & 14 & in tact; no pain & halo pin site infection \\
\hline 4 & C1-2 & halo & 22 & in tact & none \\
\hline 5 & $\mathrm{C} 1-\overline{2}$ & halo & 2 & in tact & none \\
\hline 6 & $\mathrm{C1-2}$ & halo & 14 & mild head tilt to rt; intact & $\begin{array}{l}\text { halo pin site infection; } \mathrm{c}-2 \text { on } \\
\mathrm{c}-3 \text { subluxation }\end{array}$ \\
\hline 7 & $\mathrm{C1}-2$ & halo & 7 & in tact & none \\
\hline 8 & $\mathrm{C1}-2$ & halo & 10 & in tact & none \\
\hline 9 & $\mathrm{c} 1-2$ & halo & 14 & $\begin{array}{l}\text { rt dysmetria improwing; } \\
\text { rt side hyperrefle via }\end{array}$ & none \\
\hline 10 & $\infty \mathrm{c}-\mathrm{C}$ & halo & 12 & in tact & none \\
\hline 11 & no fusion & halo & & in tact & $\begin{array}{l}\text { halo pin site infection; early halo } \\
\text { removal; failed fusion }\end{array}$ \\
\hline & $\infty \mathrm{c}-\infty$ & halo & 28 & in tact & \\
\hline 12 & $\begin{array}{l}\text { no fusion } \\
\text { c1-2 }\end{array}$ & $\begin{array}{l}\text { halo } \\
\text { halo }\end{array}$ & 32 & It UE 45; It hyperreflexa & postop slippage \\
\hline 13 & C1-2 & halo & 4 & in tact & none \\
\hline 14 & C1-2 & halo & 20 & in tact & none \\
\hline 15 & $\mathrm{C1}-2$ & halo & 28 & in tact & none \\
\hline 16 & NÁ & NA & 14 & $\begin{array}{l}\text { dysphagia im proving; } \\
\text { hemi paresis resol ved }\end{array}$ & none \\
\hline & $\mathrm{C1}-2$ & halo & & & \\
\hline 17 & $\mathrm{C1}-2$ & halo & 6 & in tact & none \\
\hline 18 & $c 1-2$ & halo & 7 & in tact & halo pin site infection \\
\hline 19 & $\mathrm{C1-2}$ & halo & 7 & in tact & none \\
\hline 20 & $\begin{array}{l}\text { no fusion } \\
\mathrm{Co}-\mathrm{C} 3\end{array}$ & $\begin{array}{l}\text { halo } \\
\text { halo }\end{array}$ & 29 & in tact & graft resorption; fusion failure \\
\hline 21 & $\mathrm{ac}-\mathrm{C}$ & halo & 9 & $\begin{array}{l}\text { dysarthria im proving; } \\
\text { hemi plegia resol wed; } \\
\text { hyperreflexa. }\end{array}$ & none \\
\hline 22 & no fusion & halo & 32 & tilat LE hyperreflexia & $\begin{array}{l}\text { fusion failure; further surgery } \\
\text { deferred by parents } \& \text { physician }\end{array}$ \\
\hline 23 & C1-2 & collar & 13 & in tact & none \\
\hline 24 & $\mathrm{C1}-2$ & halo & 4 & in tact & none \\
\hline 25 & $\mathrm{C1}-2$ & halo & 4 & in tact & halo pin site infection; pin moved \\
\hline
\end{tabular}

${ }^{*} \mathrm{LE}=$ lower extremity; $\mathrm{NA}=$ not applicable; $\mathrm{C}=$ occiput; UE = upper extremity.

\section{Neurological Examination}

No patient experienced neurological decline after surgery. Of the 10 patients with abnormal neurological findings, three displayed hyperreflexia without a deficit, which resolved in two patients and remained unchanged in the third. One patient, who presented with normal motor function but decreased proprioception in his lower extremities, had normal responses when examined 7 months after surgery. Three children presented with deficits referable to regions of the neuroaxis above the foramen magnum. An 8-year-old boy with congenital atlantoaxial instability presented with dysphagia and mild hemiparesis. Fourteen months after odontoidectomy and atlantoaxial fusion, his hemiparesis had resolved and his dysphagia was improving. Another patient presented with cerebellar infarctions due to atlantoaxial instability, an association previously reported by others.[2] At the age of 9 years, this patient developed unilateral vertebral artery dissection (which led to occlusion) associated with os odontoideum 
and instability. He presented with unilateral nuclear facial weakness, dysmetria, hemiparesis, and repeated emesis. After atlantoaxial fusion, these deficits resolved and his only limitation was moderate dysmetria. A third patient who had survived atlantooccipital dislocation caused by a motor vehicle accident presented with deficits of the ninth to 12th cranial nerves and with hemiparesis. Nine months after an occiput-C2 fusion, she showed improvement of her hemiparesis and had only a moderately severe dysarthria. Two other patients presented with hemiparesis. One experienced resolution of his deficits and the other had improved at the latest follow-up review. Overall, of the 10 patients presenting with abnormalities on initial neurological examination, five experienced resolution and four improvement of the original findings, whereas one patient presenting with hyperreflexia only showed no improvement at a mean clinical follow-up period of 17 months (range 2-32 months).

\section{Postoperative Complications}

Repeated Operation. Repeated operation was required in three patients. A 16-year-old boy with os odontoideum sustained an early loss of reduction in the 1st week after undergoing a Gallie procedure; he underwent a Brooks procedure with subsequent fusion. No additional autologous bone was harvested for the second procedure. A 4-year-old girl with os odontoideum developed multiple halo pin site infections, leading to early removal of the hardware at 4 weeks. Her fusion failed, being associated with a recurrence of $12 \mathrm{~mm}$ of movement of $\mathrm{C}-1$ on to $\mathrm{C}-2$. She then underwent an occiput-C 2 fusion procedure that required additional autologous as well as allograft bone 10 weeks after the first operation. Radiographic follow-up evaluation at 16 months showed fusion extending to include C-3 as well. This was the only case in which fusion extended beyond the construct. A 9-year-old girl with a Type II fracture showed evidence of resorption of her autologous bone graft, severe thinning of C-1 and complete erosion of the posterior ring of C-2 by both multistranded cables 3 months after her initial surgery. After her pathological hypermobility did not respond to further halo immobilization, an occiput-C 3 procedure with pediatric Cotrel-Dubousset rods and additional autologous bone resulted in successful fusion.

Of the four children who underwent primary occiput-C2 fusion, fusion was successful in three. Two months after surgery, the fourth, a 14-year-old girl with instability associated with trisomy 21 , experienced complete erosion of the ring of $\mathrm{C}-2$ where a multistranded cable had been positioned. This appeared to be caused by a sawlike effect of the cable on the bone caused by micromotion at the level of fusion despite postoperative halo immobilization. Thirteen months after surgery, flexion-extension radiographs showed $5 \mathrm{~mm}$ of movement between $\mathrm{C}-1$ and $\mathrm{C}-2$, a reduction from $11 \mathrm{~mm}$; however, the patient's parents declined further operation. This complication associated with multistranded cable occurred in two of the six cases in which it was used, despite the avoidance of overtightening. In both cases there was a clear indication for repeated operation, although surgery was declined in one case.

Orthosis Complications. Complications related to the use of a halo device occurred in seven of the 24 patients in whom it was used, two of whom required repeated operation. Slippage in the halo with resultant loss of reduction occurred in one patient, a 16-year-old boy with os odontoideum who required two surgeries. Of the six patients in whom a pin site infection occurred, the device was removed early in two after multiple attempts at infection control had failed. In one of the two, a 4-year-old girl with os odontoideum, the halo was removed after 4 weeks, and as a result she required a second operation for fusion.

\section{DISCUSSION}

As noted by Smith and colleagues,[25] fusion of the upper cervical spine in the pediatric population has 
rarely been addressed in previous communications. We present 25 patients who underwent such a procedure at our institution. Fusion was achieved in all but one patient; however, a second operation was required in three patients. The four patients in whom the first procedure failed varied in age and diagnosis, and their procedures were performed by different surgeons using different techniques. The mean of their ages $(4,9,14$, and 16 years) exceeds that of the whole series by only 18 months. The four patients were surgically treated by three different surgeons. The fusion methods also varied: one patient underwent a Gallie fusion, one an occiput-C2 fusion, and two underwent Brooks fusions. Autologous iliac crest bone grafts and postoperative halo immobilization were used in all four patients. No trend toward greater blood loss or longer operative time, which may suggest a technically more difficult case, could be found.

Each case of fusion failure was associated with a complication of either postoperative immobilization or internal fixation. In two of the six cases in which multistranded cables were used, the cable appeared to have sawed through the lamina of C-2. It should be emphasized that the cables in these patients were not overtightened and both patients were also immobilized in a halo vest. Based on the intraoperative appearance of the rings of $\mathrm{C}-1$ and $\mathrm{C}-2$ in the one patient who underwent repeated operation, it was clear that the braided wires had eroded through the posterior arches at these levels. The bone medial to the wires at C-2 had largely been resorbed. The mechanism for this effect may be either avascular necrosis of the intervening bone or micromotion-induced sawing of the cable through the bone, which is inherently thinner and more fragile than that of adults. Accordingly, we have stopped using this type of cable in young children and have returned to using 18-gauge wire.

The other two fusion failures were associated with halo complications. In one case, severe, multiple pin site infections lead to early removal of the halo after 4 weeks. Despite subsequent immobilization in a rigid cervical collar, this patient later required occiput-C2 fusion. Another patient immobilized in a halo suffered an early loss of reduction that could not be regained nonsurgically, leading to a second operation 9 days after the first. Fusion was ultimately achieved in both patients.

\section{Postoperative Immobilization}

This series raises an additional issue concerning the optimum mode of cervical immobilization after a fusion procedure. Although some surgeons have favored using a hard collar after a Brooks-type operation,[25] our results suggest that this may not provide optimum immobilization. While placed in a halo device, two of 24 children had early loss of alignment, as did one of the two children in whom the halo was removed early because of pin site complications. It is our belief that in a potentially active pediatric patient who may not obey the same activity restrictions as an adult, rigid external immobilization is needed to minimize intersegmental micromotion that can interfere with a successful fusion. Although a Minerva cast may provide a comparable degree of immobilization,[17] this type of brace is often tolerated less well than a halo.

A hard collar might provide adequate immobilization in appropriately selected older children who may be candidates for highly rigid internal constructs such as C1-2 transarticular screws or an odontoid screw (for an acute odontoid fracture).[3,7,16,28] These techniques have only been in widespread use for the last few years and are often not applicable in preadolescent children, who may lack adequate bone thickness for good screw purchase. None of our recently treated patients has been a good candidate for such procedures.

Down's Syndrome 
Four of the patients in our series had trisomy 21 (Down's syndrome), which can be associated with either atlantoaxial or atlantooccipital hypermobility.[19,20,22-24,27,29] Although most of the literature concerning this association deals primarily with instability of $\mathrm{C} 1-2$, instability at occiput-C1 must also be ruled out in each patient prior to atlantoaxial fusion or greater instability may result. This point is well illustrated in a study by Menezes and Ryken[20] in 1992, in which they described two adolescents with instability at both segments who progressed to develop basilar invagination following fusion only at the atlantoaxial level. Of the four patients in our series with trisomy 21, two had hypermobility at both levels and underwent occiput-C2 fusion. Fusion failure associated with the use of multistranded cable occurred in one of these patients. Fusion was successful in both patients who underwent atlantoaxial fixation. Although neither patient developed postoperative atlantooccipital hypermobility, one does have a fixed 3-mm C-2 on-C-3 anterior spondylolisthesis that was not present preoperatively; however it has not required further treatment. The presence of hypermobility at two levels in two of the four children with trisomy 21 in this series further illustrates the importance of determining whether craniocervical instability is present prior to atlantoaxial fusion in these patients.

\section{CONCLUSIONS}

We conclude that posterior upper cervical fusion in the pediatric population, when coupled with rigid external immobilization, has a high rate of success if properly performed. Because fusion failures may result from inadequate postoperative immobilization with resultant intersegmental micromotion, we favor continuing rigid immobilization until a solid fusion mass is visible radiographically. We also conclude that multistranded cable should be used for such patients with caution because the cable may erode through the underlying lamina before a solid fusion can occur.

\section{References}

1. Apple JS, Kirks DR, Merten DF, et al: Cervical spine fractures and dislocations in children. Pediatr Radiol 17:45-49, 1987

2. Bhatnagar M, Sponseller PD, Carroll C IV, et al: Pediatric atlantoaxial instability presenting as cerebral and cerebellar infarcts. J Pediatr Orthop 11:103-107, 1991

3. Brockmeyer D, Apfelbaum R, Tippets R, et al: Pediatric cervical spine instrumentation using screw fixation. Pediatr Neurosurg 22:147-157, 1995

4. Brooks AL, Jenkins EB: Atlanto-axial arthrodesis by the wedge compression method. J Bone Joint Surg (Am) 60:279-284, 1978

5. Burgos-Vargas R, Clark P: Axial involvement in the seronegative enthesopathy and arthropathy syndrome and its progression to ankylosing spondylitis. J Rheumatol 16:192-197, 1989

6. Burgos-Vargas R, Naranjo A, Castillo J, et al: Ankylosing spondylitis in the Mexican mestizo: patterns of desease according to age at onset. J Rheumatol 16:186-191, 1989

7. Coyne TJ, Fehlings MG, Wallace MC, et al: C1-C2 posterior cervical fusion: long-term evaluation of results and efficacy. Neurosurgery 37:688-693, 1995

8. Dyck P: Os odontoideum in children: neurological manifestations and surgical management.

Neurosurgery 2:93-99, 1978 
9. Fielding JW, Hensinger RN, Hawkins RJ: Os odontoideum. J Bone Joint Surg (Am) 62:376-383, 1980

10. Floman Y, Kaplan L, Elidan J, et al: Transverse ligament rupture and atlanto-axial subluxation in children. J Bone Joint Surg (Br) 73:640-643, 1991

11. Foster HE, Cairns RA, Burnell RH, et al: Atlantoaxial subluxation in children with seronegative enthesopathy and arthropathy syndrome: 2 case reports and a review of the literature. J Rheumatol 22:548-551, 1995

12. Fox MW, Onofrio BM, Kilgore JE: Neurological complications of ankylosing spondylitis. J Neurosurg 78:871-878, 1993

13. Hadley MN, Zabramski JM, Browner CM, et al: Pediatric spinal trauma. Review of 122 cases of spinal cord and vertebral column injuries. J Neurosurg 68:18-24, 1988

14. Hamilton MG, MacRae ME: Atlantoaxial dislocation as the presenting symptom of ankylosing spondylitis. Spine 18:2344-2346, 1993

15. Hensinger RN, Fielding JW, Hawkins RJ: Congenital anomalies of the odontoid process. Orthop Clin North Am 9:901-912, 1978

16. Jeanneret B, Magerl F: Primary posterior fusion C1/2 in odontoid fractures: indication, technique, and results of transarticular screw fixation. J Spinal Disord 5:464-475, 1992

17. Johnson RM, Hart DL, Simmons EF, et al: Cervical orthoses. A study comparing their effectiveness in restricting cervical motion in normal subjects. J Bone Joint Surg (Am) 59:332-339, 1977

18. Lally KP, Senac M, Hardin WD Jr, et al: Utility of the cervical spine radiograph in pediatric trauma. Am J Surg 158:540-542, 1989

19. Martel W, Tishler JM: Observations on the spine in mongoloidism. AJR 97:630-638, 1966

20. Menezes AH, Ryken TC: Craniovertebral abnormalities in Down's syndrome. Pediatr Neurosurg 18:24-33, 1992

21. Orenstein JB, Klein BL, Gotschall CS, et al: Age and outcome in pediatric cervical spine injury: 11 year experience. Pediatr Emerg Care 10:132-137, 1994

22. Pueschel SM, Herndon JH, Gelch MM, et al: Symptomatic atlantoaxial subluxation in persons with Down syndrome. J Pediatr Orthop 4:682-688, 1984

23. Pueschel SM, Scola FH, Perry CD, et al: Atlanto-axial instability in children with Down syndrome. Pediatr Radiol 10:129-132, 1981

24. Rizzolo S, Lemos MJ, Mason DE: Posterior spinal arthrodesis for atlantoaxial instability in Down syndrome. J Pediatr Orthop 15:543-548, 1995

25. Smith MD, Phillips WA, Hensinger RN: Fusion of the upper cervical spine in children and adolescents. An analysis of 17 patients. Spine 16:695-701, 1991

26. Spierings ELH, Braakman R: The management of os odontoideum. Analysis of 37 cases. J Bone 
Joint Surg (Br) 64:422-428, 1982

27. Spitzer R, Rabinowitch JY, Wybar KC: A study of the abnormalities of the skull, teeth and lenses in mongolism. Can Med Assoc J 84:567-572, 1961

28. Stillerman CB, Wilson JA: Atlanto-axial stabilization with posterior transarticular screw fixation: technical description and report of 22 cases. Neurosurgery 32:948-955, 1993

29. Tishler JM, Martel W: Dislocation of the atlas in mongolism. Preliminary report. Radiology 84:904-906, 1965

30. Tredwell SJ, Newman DE, Lockitch G: Instability of the upper cervical spine in Down syndrome. J Pediatr Orthop 10:602-606, 1990

Manuscript received February 25, 1997.

Accepted in final form June 23, 1997.

Address reprint requests to: Ian F. Pollack, M.D., Department of Neurosurgery, Children's Hospital of Pittsburgh, 3705 Fifth Avenue, Pittsburgh, Pennsylvania 15213. 